\title{
ВИЗНАЧЕННЯ ВПЛИВУ СТРУКТУРИ МЕРЕЖІ НА РОЗПОДІЛ ВУЗЛОВИХ НАПОРІВ
}

\author{
DETERMINATION OF THE IMPACT OF THE NETWORK \\ STRUCTURE ON NODE PRESSURE DISTRIBUTION
}

\author{
Добровольська О.Г., к.т.н., (Запорізький національний \\ університет)
}

\section{Dobrovolska O.G., Ph.D. in Engineering, (Zaporizhzhya National University)}

Анотація. Досліджено вплив окремих ділянок водопровідної мережі на надійність водопостачання в нормальних і аварійних умовах з врахуванням умов живлення та структури мережі. Представлені результати досліджень особливостей утворення та зміни площі зон недостатнього напору з урахуванням гідравлічних характеристик мережі. Визначені завдання, які має вирішувати система управління потокорозподілом на стадії проектування мереж. За результатами досліджень виконано очінку умов водопостачання при утворенні зон недостатнього напору.

Summary In the event of an accident on certain parts of the network, the operational redistribution of flows in it allows to reduce significantly the negative consequences of the accident. The effect will be greater the shorter the time between the start of the accident and the measures taken. The general unsatisfactory condition of the water supply networks in Ukraine and the high incidence of them require from the dispatching services of the utility companies prompt response to eliminate the consequences of emergencies. However, most utilities do not provide the ability to make rapid changes to the flow management system, which impairs its efficiency. Given the above, it is relevant to continue research on the influence of network structure on the distribution of nodal head.

In this work the influence of separate sections of the water supply network on the dynamics of nodal pressures for different conditions of supply is investigated. The results of investigations of peculiarities of formation and change of the area of areas of insufficient head with the account of emergency situations for networks with different structure are presented.

The tasks to be solved by the flow management system at the design stage of the networks are identified. According to the results of the researches, the conditions of water supply were formed when the zones of insufficient head were formed

The research methodology consisted of the following stages: development of initial schemes; performance of hydraulic calculations at normal network modes; modeling of emergencies; performance of hydraulic calculations in emergency situations and analysis of their results; analysis of the joint work of pumps and water supply systems. 
Modeling and analysis of pressure zones in the network, depending on the need to change the number and location of pressure control units. A distinctive feature of this approach to flow management is timely prevention of emergencies, setting the optimum network structure and operating modes. The proposed methodology for managing the distribution can be implemented in the work of dispatching services of utility companies.

Ключові слова: водопровідна мережа, потокорозподіл, оптимізачиія управління, зони недостатнього тиску.

Keywords:: water supply network, distribution, control optimization, areas of insufficient pressure.

Постановка проблеми. Функціонування водопровідних мереж відбувається під впливом різних зовнішніх факторів. Ці фактори змінюють стан мереж, що впливає на умови управління потокорозподілом в них. Структура водопровідної мережі відображає зв'язки між іiі основними функціональними елементами. При аварії на окремих ділянках мережі оперативний перерозподіл потоків в ній дозволяє суттєво зменшити негативні наслідки аварії. Ефект буде тим вищий, чим термін між початком аварії i прийнятими заходами буде коротшим. Загальний незадовільний стан водопровідних мереж в Україні та висока аварійність на них вимагають від диспетчерських служб комунальних підприємств оперативного реагування для ліквідації наслідків аварійних ситуацій. Однак, більшість комунальних підприємств не забезпечують можливості оперативного внесення змін в систему управління потокорозподілом, що погіршує ефективність іiі роботи. Враховуючи вищезазначене, актуальним $\epsilon$ продовження досліджень впливу структури мережі на розподіл вузлових напорів.

Аналіз відомих досліджень. Основними профілактичними заходами попередження аварійних ситуацій на водопровідних мережах є візуальний контроль та методи, пов'язані 3 використанням вимірювального обладнання. Стан аварійності з урахуванням матеріалу трубопроводів та особливості управління системою водопостачання міст в критичних ситуаціях були проаналізовані в роботах закордонних фахівців [1-3]. Як свідчить досвід вітчизняних фахівців $[4,5]$, недостатня надійність трубопроводів водопровідних мереж негативно позначається на якості питної води.

За результатами досліджень [6] було запропоновано виконувати вибір варіанту трасування кільцевої мережі за мінімальним значенням точки граничної надійності, показано, як змінюється надійність структур кільцевих мереж при введенні нових ділянок та вузлів, обгрунтовано ідею, що забезпечити надійність при реконструкції мережі можливо шляхом введення нових ділянок, а не вузлів. За рахунок зменшення наднормативних напорів, їх стабілізації і максимальному наближенні до номінальних можна зменшити втрати води через витоки на величину до 
6\%, що при існуючих тарифах на воду дозволить суттєво скоротити експлуатаційні витрати [7]. Доцільність моделювання зон розподілу тиску підтверджується висновками фахівців про застосування активного моніторингу тиску для виявлення прихованих витоків, представлені в роботі [8]. Висновками досліджень, представленими в роботі [9], підтверджується, що для зменшення надмірного тиску також необхідно визначення таких зон. Недостатня увага до своєчасної реконструкції та модернізації елементів та споруд у системі водопостачання призводить до помітного збільшення кількості аварій, у тому числі таких, які можуть поставити на межу екологічної катастрофи цілі регіони. Враховуючи вищезазначене, актуальним $є$ продовження досліджень впливу окремих ділянок мережі на розподіл вузлових напорів, своєчасного резервування найбільш вагомих ділянок в структурі водопровідної мережі.

Мета статті. Метою роботи є дослідження впливу окремих ділянок на динаміку вузлових напорів для мереж з різню структурою та умовами живлення. Це направлено на забезпечення мінімально необхідних значень тисків у вузлах водопровідних мереж. Для визначення впливу структури мережі на іï гідравлічні характеристики були застосовані методи математичного моделювання потокорозподілу у водопровідній мережі, методи гідравлічних розрахунків водопровідних мереж.

Постановка завдання. Досягнення мети передбачає виконання ряду задач:

- вибір об'єктів дослідження (таблиця1) - схем водопровідних мереж 3 різними структурами та формування вихідних даних: водопровідна мережа за схемою А із 12 контурів, 21 вузла та 32 ділянок; водопровідна мережа за схемою Б із 9 контурів, 16 вузлів та 24 ділянок;

- виконання гідравлічних розрахунків за вибраними схемами, враховуючи аварійні ситуації для різних структурних схем та варіантів живлення;

- визначення п'єзометричних позначок та вузлових напорів для розглянутих варіантів моделювання аварійних ситуацій;

- визначення впливу окремих ділянок мережі на розміри та розташування зон недостатнього напору для різних варіантів її структури та живлення: для мережі за схемою А було промодельовано 12 аварійних ситуацій для кожної із трьох структур мереж, які відрізнялись довжиною ділянок за напрямами 1-4-7-10-13-16-19; 2-5-8-11-14-17-20; 3-6-9-12-15-1821 при постійній загальній витраті; для мережі за схемою Б було промодельовано 11 аварійних ситуацій для трьох варіантів живлення мережі;

- визначення вільних напорів у вузлах мережі відносно точки живлення згідно із розглянутими варіантами підключення водоводів при зміні гідравлічних характеристик мережі. 
Таблиця 1.

Характеристика водопровідних мереж

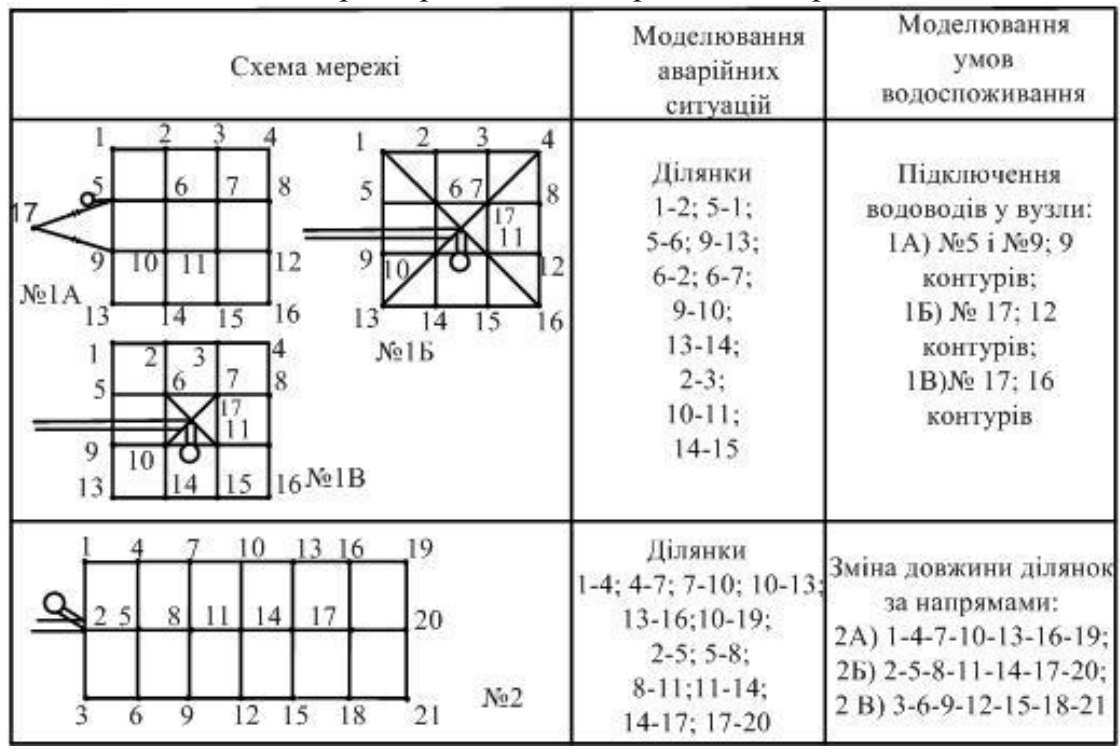

Результати досліджень гідравлічних характеристик мережі. За результатами гідравлічного розрахунку для кожного варіанту моделювання аварійних ситуацій були встановлені зони недостатнього напору, межі яких визначені по розташуванню вузлів із напором, що відповідає умові:

$$
H_{B i}<H_{H},
$$

де $H_{s i}$ - значення вільного напору в і-му вузлі, м;

$H_{H}$ - значення необхідного напору [11, п. 6.3.1],м.

Як приклад, площадні графіки утворення зон недостатнього напору у водопровідній мережі за схемою №1 при аварії на ділянці 5-6 для різних умов живлення представлені на рис. 1. Площі зон недостатнього напору відрізняються у співвідношенні 6,1:1,3:1 для різних варіантів підключення водоводів, що пояснюється різним навантаженням аварійної ділянки. Площу цих зон можна суттєво зменшити при подачі живлення у центральні вузли мережі. Зміна структурної схеми мережі при однакових умовах живлення не має суттєвого впливу на розмір цих зон при аналогічних аварійних ситуаціях. 


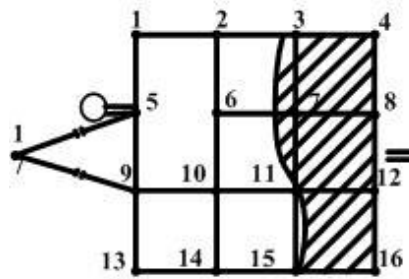

A)

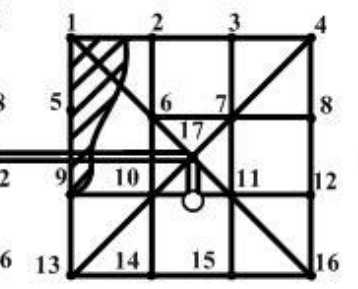

Б)

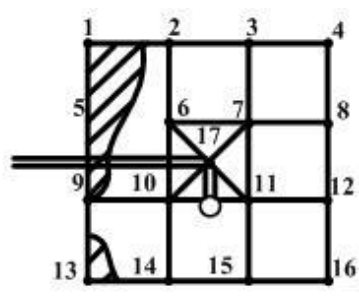

B)

зони недостатнього напору

Рис. 1. Зони недостатнього напору з урахуванням зміни структури мережі №1 для різних варіантів живлення мережі: а - подача води у взули 5 і 9; б, в - подача води у вузол 17

На рис. 2 представлені процеси утворення можливих зон недостатніх напорів при аварії на ділянці для мережі за схемою №2 3 різною довжиною ділянок, площі цих зон мають співвідношення та несуттєво відрізняються $(1: 1,1: 1)$.
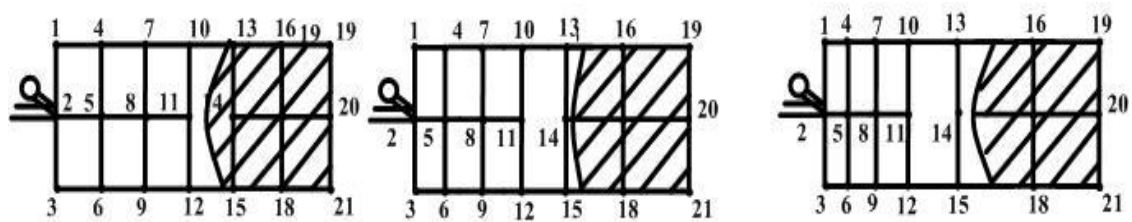

Рис. 2. Зони недостатнього напору з урахуванням зміни структури мережі №2 при живленні мережі у вузол2

Як видно 3 діаграми на рис. 3А, найменша площа зони 3 недостатнім напором $\left(\mathrm{F}_{\text {3.н.н }} / \mathrm{F}_{\text {заг }}=2-15 \%\right)$ утворюється при умові живлення $\mathrm{y}$ центральний вузол 17 , що пояснюється меншим навантаженням початкових ділянок та більш рівномірним розподілом витрати води. Розмір зони недостатнього напору не перевищує 20\% від загальної площі (схеми №1-б, в).

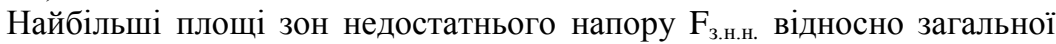
площі $\mathrm{F}_{\text {заг. }}\left(\mathrm{F}_{\text {3.н.н }} / \mathrm{F}_{\text {заг }}=52-70 \%\right)$ слід очікувати при аваріях на ділянках 3 найбільшим навантаженням(ділянки 2-5; 5-8; 8-11 для мережі за схемою №2). При однакових умовах живлення співвідношення між площами цих зон для схем мереж з різною довжиною ділянок (рис. ЗБ) відрізняється в межах 5-20\%. 


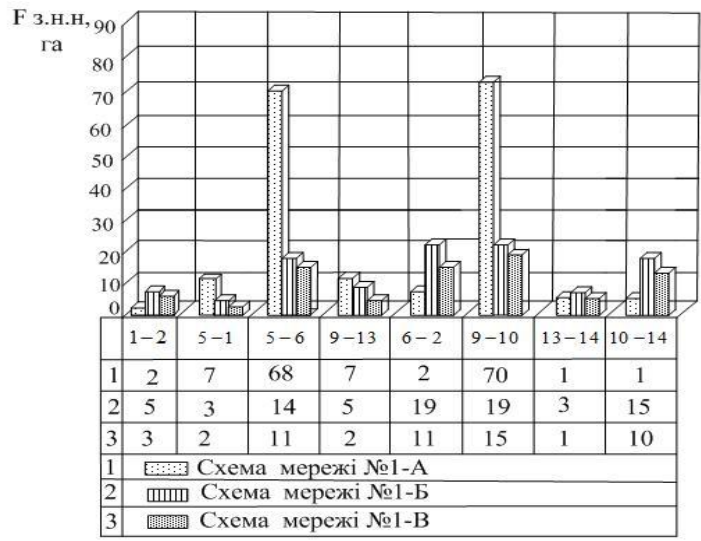

A)

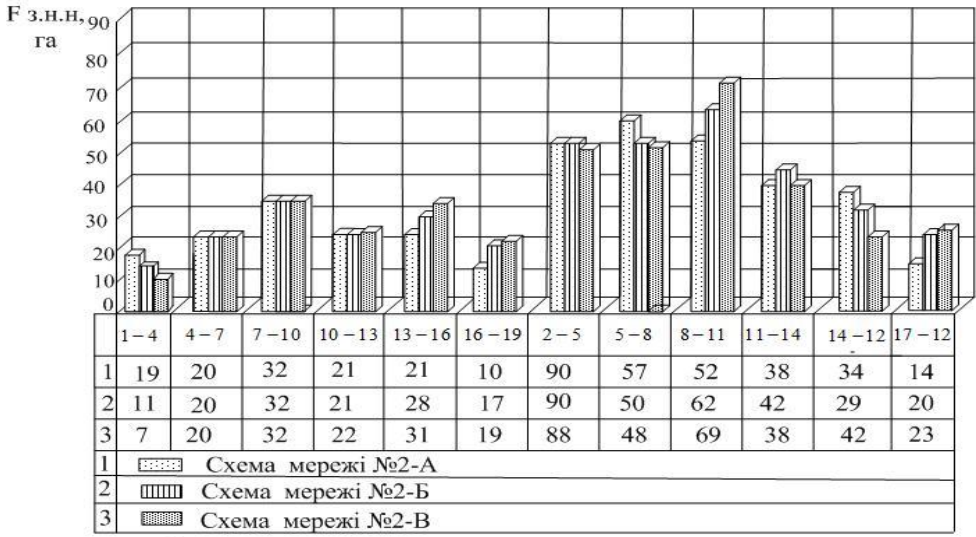

Б)

Рис. 3. Зміна площі зон недостатнього напору $\mathrm{F}_{\text {з.н.н }} 3$ урахуванням зміни структури мережі А) та зміни умов живлення Б)

Моделювання ситуацій, що зумовлюються змінами стану водопровідних мереж та умовами їх функціонування при експлуатації дозволяє оптимізувати роботу мережі при іiі проектуванні. Аналіз розташування та розмірів зон недостатнього напору на стадії проектування мереж дозволяє обгрунтувати вибір оптимального варіанту іiі живлення.

Висновки.1. Виконано теоретичне обгрунтування щодо процесу утворення зон недостатнього напору з урахуванням аварійних ситуацій в мережі.

2. Виконано оцінку впливу зміни гідравлічних характеристик водопровідної мережі на розміри зон недостатнього напору з урахуванням iї структури. 
3. На стадії проектування водопровідної мережі крім критичної точки слід передбачати додаткові 2-3 контрольних вузла, розташованих на межі можливих зон недостатнього напору, моделювання утворення яких теж слід виконувати на стадії проектування мережі.

4. Аналіз гідравлічних характеристик роботи мережі з урахуванням іiі структури на стадії проектування дає можливість забезпечити надійність ії роботи при розробці реальних систем водопостачання.

При керуванні потокорозподілом у водопровідних мережах необхідна візуальна оцінка очікуваної зони недостатнього напору. Це дозволяє працівникам диспетчерських служб комунальних підприємств не тільки візуально оцінити ситуацію, але й прийняти рішення за результатами розрахунків. При $\mathrm{F}_{\text {з.н.н }} / \mathrm{F}_{\text {заг }}<40 \%$ достатньо введення одного контрольного вузла 3 найменшим вільним напором 3 числа тих, що розташовані на межі очікуваної зони, при $\mathrm{F}_{\text {з.н.н }} / \mathrm{F}_{\text {заг }}=40-60 \%$ необхідно обладнання 2-3 додаткових контрольних вузлів, що вибираються за вказаними критеріями.[11].

\section{References}

1. Tchorzewska-Cieslak B. Failure risk analysis in the collective water supply systems in crisis situations. Journal of Polish Safety and Reliability Association. 2013.Vol.1(4), 129-136.

2. Tchorzewska-Cieslak B. Water supply of urban agglomeration in crisis situation. Journal of Polish Safety and Reliability Association. 2014. Vol.5, 143-155.

3. Tchorzewska-Cieslak B. Crisis situation management issues in urban areas water supply. Journal of Polish Safety and Reliability Association Summer Safety and Reliability Seminars. 2015. Vol.2, 135 - 145.

4. Klimentiev I.M., 2011. Suchasnyi stan vodopostachannia naselennia ta osnovni problemy zakhodiv shchodo yoho optymizatsii. Vodopostachannia ta vodovidvedennia. Kyiv: KNUBA, 2011. Vol.3, $57-58$.

5. Novokhatnyi V.H. Nadezhnost vodovodov system vodosnabzhenyia. MOTROL. Commission of motorization and energet-ic in agriculture. Polish Academy of sciences. Lublin - Rzeszow, 2013.Vol.15. 101-108.

6. Novokhatnii V. H. Nadiinist funktsionuvannia podavalno-rozpodilnoho kompleksu system vodopostachannia: avtoref. dys. ... dokt. tekhn. nauk: 05.23.04. Kyiv. 2012. $32 \mathrm{~s}$.

7. Tkachuk O. A. Udoskonalennia system podachi i rozpodilennia vody naselenykh punktiv / O. A. Tkachuk. Rivne: NUVHP, 2008.301s.

8. Karathanasi, I. (2016). Constantinos Papageorgakopoulos Development of a Leakage Control System at the Water Supply Network of the City of Patras. Procedia Engineering, 162, 553-558.

9. Gençoğlu, G., Merzi, N. (2017). Minimizing Excess Pressures by Optimal Valve Location and Opening Determination in Water Distribution Networks. Procedia Engineering, 186. P. 319-326.

10. Vodopostachannia. Zovnishni merezhi ta sporudy. DBN V.2.5-74:2013, $172 \mathrm{s.}$ 
11. Dobrovol's'ka O. Development of procedure to control flow distribution in water supply networks in real time. Eastern-European Journal of Enterprise Technologies. 2018. № 6/8(96). C. 17-24.

\section{Список використаної літератури}

1. Tchorzewska-Cieslak B. Failure risk analysis in the collective water supply systems in crisis situations. Journal of Polish Safety and Reliability Association. 2013.Vol.1(4), 129-136.

2. Tchorzewska-Cieslak B. Water supply of urban agglomeration in crisis situation. Journal of Polish Safety and Reliability Association. 2014. Vol.5, 143-155.

3. Tchorzewska-Cieslak B. Crisis situation management issues in urban areas water supply. Journal of Polish Safety and Reliability Association Summer Safety and Reliability Seminars. 2015. Vol.2, 135 - 145.

4. Кліментьєв I.М., 2011. Сучасний стан водопостачання населення та основні проблеми заходів щодо його оптимізації. Водопостачання та водовідведення. Київ: КНУБА, 2011. Vol.3, $57-58$.

5. Новохатний В.Г. Надежность водоводов систем водоснабжения. MOTROL. Commission of motorization and energet-ic in agriculture. Polish Academy of sciences. Lublin - Rzeszow, 2013.Vol.15. 101-108.

6. Новохатній В. Г. Надійність функціонування подавально-розподільного комплексу систем водопостачання: автореф. дис. ... докт. техн. наук: 05.23.04. Київ. 2012. 32 с.

7. Ткачук О. А. Удосконалення систем подачі і розподілення води населених пунктів / О. А. Ткачук. Рівне: НУВГП, 2008. 301с.

8. Karathanasi, I. (2016). Constantinos Papageorgakopoulos Development of a Leakage Control System at the Water Supply Network of the City of Patras. Procedia Engineering, 162, 553-558.

9. Gençoğlu, G., Merzi, N. (2017). Minimizing Excess Pressures by Optimal Valve Location and Opening Determination in Water Distribution Networks. Procedia Engineering, 186. P. 319-326.

10. Водопостачання. Зовнішні мережі та споруди. ДБН В.2.5-74:2013, 172 с.

11. Добровольська O. Development of procedure to control flow distribution in water supply networks in real time. Eastern-European Journal of Enterprise Technologies. 2018. № 6/8(96). C. 17-24. 